\title{
La experiencia totalitaria en Europa después de la IIGM. Voces de mujer: exilio, denuncia y escritura en lengua francesa. Oana Orlea y Rouja Lazarova ${ }^{1}$
}

\author{
Margarita Alfaro AmIEIRO \\ Departamento de Filología Francesa \\ Universidad Autónoma de Madrid \\ margarita.alfaro@uam.es
}

\begin{abstract}
RESUMEN
La experiencia totalitaria en Europa después de la IIGM deja una larga estela de consecuencias que se caracterizan, desde la perspectiva artística y literaria, por la opresión y la falta de libertad de expresión. La vivencia del exilio a partir de los años 80 en Francia abre la posibilidad a muchos escritores de denunciar lo vivido por medio de la expresión literaria en lengua francesa. Nuestro análisis se centra en el estudio del universo narrativo de las autoras Oana Orlea (1935), de origen rumano, y Rouja Lazarova (1968), de origen búlgaro, exiliadas en Francia en 1980 y 1991, respectivamente. Ambas autoras, en el marco de la ficción, introducen voces de mujer y proyectan su experiencia autobiográfica antes y después del exilio y adoptan la palabra para denunciar los abusos del régimen totalitario.
\end{abstract}

Palabras clave: totalitarismo, exilio, escritura francófona, Oana Orlea, Rouja Lazarova, denuncia.

Totalitarian experience in Europe after WWII. Women's Voices: exile, reporting and writing in French. Oana Orlea and Rouja Lazarova

\begin{abstract}
Totalitarian experience in Europe after WWII leaves a long trail of consequences that are characterized, from the artistic and literary perspective, by oppression and lack of freedom of expression. The experience of exile from the 80s in France opens the possibility to denounce what many writers lived through literary expression in French. Our analysis focuses on the study of narrative universe of the authors Oana Orlea (1935), of Romanian origin, and Rouja Lazarova (1968) of Bulgarian origin, exiled in France in 1980 and 1991, respectively. Both authors, in the context of fiction, introduced women's voices, cast their autobiographical experience before and after the exile and take the floor to denounce the abuses of the totalitarian regime.
\end{abstract}

Keywords: totalitarianism, exile, Francophone writing, Oana Orlea, Rouja Lazarova, report.

\footnotetext{
${ }^{1}$ Este trabajo se inscribe en el marco de los objetivos del proyecto de investigación de $\mathrm{I}+\mathrm{D}+\mathrm{i}$ del MINECO con referencia FFI2013-43483-R. 
A la historia solo parecen preocuparle los hechos, las emociones quedan siempre marginadas, no se les puede dar cabida en la historia. Pero yo observo el mundo con ojos de escritora, no de historiadora. Y siento una gran fascinación por el ser humano... (Aleksiévich 2015: 14)

\section{Presentación}

Los análisis acerca de las consecuencias que ha tenido la IIGM en Europa han puesto de manifiesto que fue un enfrentamiento bélico que además de sumergir a toda la población europea, a excepción de España y Portugal, en un proceso de aniquilación durante el tiempo de la guerra, con posterioridad surgieron fronteras, invasiones y posiciones ideológicas y políticas que aislaron a los países llamados de la Europa del Este a consecuencia del sometimiento que la Unión Soviética ejerció sobre ellos debido a la proximidad geográfica.

En nuestro análisis abordaremos una manifestación singular de los reflejos de la guerra en su relación con la expresión literaria y por lo tanto con la capacidad de adoptar la palabra para expresar la experiencia totalitaria vivida en los países de la Europa del Este. Para ello focalizaremos nuestro trabajo en el estudio de dos escritoras originarias de dos países que vivieron durante varias décadas la opresión de un sistema que habiendo querido anular la posibilidad de expresión y la imposición ideológica no lo logra plenamente. Se trata de dos escritoras que adoptan el exilio geográfico y potencian por ello su necesidad de escribir y contar lo vivido gracias a la incorporación de otra lengua distinta a la propia. Así pues, Oana Orlea y Rouja Lazarova, como otras escritoras previamente, entre ellas Agota Kristof, de origen húngaro exiliada en la Suiza francófona desde 1956, o Julia Kristeva, de origen búlgaro, que llega a París en 1966, se exilian en Francia y nos van a permitir situarnos en el fenómeno del desplazamiento por razones de tipo ideológico. Todas ellas enriquecen el campo de la literatura francófona del exilio a partir de los años 1980 a consecuencia de los sistemas totalitarios y muestran su capacidad para poner en cuestión los mitos fundadores.

Tanto Oana Orlea (Alfaro 2012a: 678-681) como Rouja Lazarova (Alfaro 2012b: 523-525), si bien pertenecen a dos generaciones diferentes, nos van a permitir ilustrar las analogías entre ellas dado que comparten un mismo proyecto escritural: introducir en el universo narrativo de sus novelas voces de mujeres inspiradas en sus propias autobiografías, de un lado, y focalizar el anhelo de denunciar los abusos cometidos en sus respectivos países por el poder totalitario, de otro lado. Ambas eligen exiliarse en Francia, país en el panorama europeo occidental considerado tradicionalmente como terre d'accueil, debido a que la lengua y la cultura francesas han estado presentes en estos países como lengua de expresión intelectual, asociada a la élite socio-cultural. En este sentido, la Francofonía presente en la Europa del Este se ha constituido, después de la IIGM, en un espacio cultural y lingüístico de resistencia cuyas temáticas más representativas han venido siendo

2 El francés ha sido, en Rumanía, Bulgaria y República Checa, una lengua de cultura y de enseñanza antes de la invasión soviética, lo que justifica la tendencia de exilio hacia Francia, en mayor 
muy significativas ${ }^{2}$. Antes del exilio: la alienación individual y colectiva a causa de la represión, la descripción de la vida cotidiana en la que se observa la miseria material y cultural así como la presión ideológica; y después del exilio: los sentimientos de pérdida y desarraigo, la incorporación de una nueva lengua de escritura, la recuperación de la memoria individual frente a la memoria de Estado y la destrucción de los mitos fundadores del comunismo. Todos estos elementos constituyen una geo-poética en lengua francesa enriquecedora de la identidad literaria europea a partir de los últimos años del siglo XX. Asimismo, ha dado lugar a una concepción novedosa, los autores desplazados se erigen en los protagonistas de la llamada literatura desterritorializada (Mathis-Moser y Mertz-Baumgartner 2012) escrita por voces venidas de otro lugar.

Así pues, el hecho del exilio en Francia como espacio de libertad dinamizará el potencial creativo que tanto Oana Orlea como Rouja Lazarova ya habían manifestado con anterioridad, ambas ya se habían servido de la palabra escrita en sus lenguas maternas, si bien bajo el filtro de la censura. En ambos casos sus producciones literarias escritas en lengua francesa se manifestarán desde la óptica de la expresión autobiográfica en la frontera de la auto-ficción expresada en voces de mujer que asumen el compromiso de tomar la palabra para denunciar el sistema de opresión después de haber vivido la experiencia del exilio. En el plano formal, observamos la emergencia de un nuevo concepto de novela como consecuencia del totalitarismo, como señala Kundera en L'art du roman (1986). Los nuevos relatos imponen la fragmentación, la heterogeneidad y la polifonía como ejes estructuradores de la experiencia vivida. Esta tendencia inherente al universo narrativo favorece la presentación de escenas dramatizadas que teatralizan el horror de la vida cotidiana y donde el hilo conductor y la unidad provienen de la voz en primera persona, con frecuencia mujeres. En este sentido es ilustrativa la reflexión que introduce la escritora de origen ucraniano, Svetlana Aleksiévich, premio Nobel de literatura, como preámbulo a nuestro análisis posterior:

Así fue el socialismo y ésa la vida que tuvimos. No solíamos hablar de ella antes. Pero ahora que el mundo ha mutado incontrovertiblemente, aquellas vidas nuestras interesan a todos, no importa cómo fueran, eran las vidas que nos tocó vivir. Yo escribo, reúno las briznas, las migas de la historia del socialismo «doméstico», del socialismo «interior»... Estudio el modo en que consiguió habitar en el espíritu de la gente. Siempre me ha atraído ese espacio minúsculo, el espacio que ocupa un solo ser humano, uno solo... Porque, en verdad, es ahí donde ocurre todo. (Aleksiévich 2015: 10)

medida, o hacia Suiza o Bélgica. En el caso de Rumanía, después de la caída del Muro de Berlín, las relaciones con Francia se intensifican y tiene lugar en Bucarest en 1998 la Conferencia Ministerial de la Francofonía y en 1999 el Salón International del Libro con la presencia de la Agencia Internacional de la Francofonía (AIF). En 2006 Bucarest será la sede de la $11^{\text {a }}$ Cumbre de la Francofonía, la primera en esta región de Europa. Uno de los temas abordados fue el sentido de la francofilia y la filiación cultural entre Francia y Rumanía. Se potencia así y se renueva la oportunidad para que otros países de esta región puedan incorporarse como observadores. Y en lo que se refiere a Bulgaria, se integra en la estructura de la Francofonía en 1991. 


\section{Oana Orlea}

Oana Orlea (pseudónimo literario Ioana-Maria Cantacuzino) nace en Rumanía en 1936. Nieta del compositor George Enescu (1881-1955) exiliado en París después de la IIGM, a los 16 años reacciona contra el comunismo y es encarcelada entre 1952 y 1954. A partir de los años 60 publica siete novelas en rumano bajo el pseudónimo de Oana Orlea: Le cheval du dimanche, 1968, La tortue orange, 1969, Un nom pour crier, 1970, Pierres sur le rivage, 1972, Cercle d'amour, 1977, Un homme rangé, 1980. Pertenece pues a la generación del sistema Ceauşescu. Los escritores de este periodo desarrollan procedimientos para burlar la censura: la ironía, la parodia y la fábula.

En 1980 llega a Francia donde pide asilo político y se integra a una larga lista de escritores de origen rumano que desde la IGM hasta la actualidad han elegido el exilio y la lengua francesa para expresar la realidad vivida ${ }^{3}$. Después de su exilio da continuidad a la escritura y cuenta con una producción literaria en Francia que puede ser considerada como significativa de un enfoque literario en el que predomina la voluntad de denunciar sus vivencias anteriores. Publica su primera novela, Un sosie en cavale (1986), que ha sido traducida al rumano en 1991, a continuación destaca su autobiografía, referida a los años 1952-1954, Les années volées. Dans le goulag roumain à 16 ans (1992) (Alfaro 2014), y más recientemente ha publicado un conjunto de relatos cortos, Rencontres sur le fil du rasoir (2007). Así pues, los núcleos temáticos expresados en el conjunto de su obra se refieren a la importancia de expresar lo vivido, esencialmente sus recuerdos de las prisiones, el Gulag, la recreación de la epopeya de su adolescencia, caracterizada por la ingenuidad y el heroísmo, la resistencia de los rumanos durante la opresión totalitaria y las consecuencias de dicho régimen para los individuos: la alienación, el miedo, la locura, el silencio, la degradación personal y emocional.

Nuestra reflexión se centrará en su primera novela escrita en lengua francesa, Un sosie en cavale (1986) ya que en ella encontramos el contexto histórico e ideológico fruto de las consecuencias para Rumanía inmediatamente después de la IIGM. El endurecimiento de las condiciones de vida así como el exilio de su abuelo y de su padre que reaccionó contra la invasión soviética activan su toma de conciencia y el nacimiento de su espíritu de confrontación, tal y como lo expresa en su autobiografía:

${ }^{3}$ La literatura rumana en Francia escrita durante el exilio evoluciona en función de las etapas políticas asociadas a la implantación del comunismo. Se pueden distinguir diferentes periodos después de la IIGM: en primer lugar, la literatura durante el mandato de Gheorghiu-Dej (1945-1965) se caracteriza por la represión generalizada y la imposición del ruso que se convierte en lengua obligatoria en la escuela. La escritura durante este periodo se hace realista y los escritores son reconocidos como la generación de los años 60. De este periodo destaca Vintila Horia (1915-1992) que adopta el exilio. Más tarde, bajo Ceauşescu (1965-1989) se sigue imponiendo la censura y se caracteriza por la expresión del horror, es la generación de la década de los 80 y tienen en común la retórica de lo horrible. Oana Orlea (1936), Maria Mailat (1946) y Matei Vişniec (1956), entre otros, eligen el exilio para escapar de la persecución. 
C'est au moment de la réforme de l'enseignement, en 1947, que j'ai commencé à ressentir le poids du nouveau régime. [...] Dans toutes les écoles, s'instaura un esprit de révolte, classique à l'âge qui était le nôtre, mais cette révolte se focalisait sur un conflit politique. Tout le monde était contre. Contre le communisme. (Orlea 1992: 14)

Oana Orlea escribe su novela en lengua francesa poco tiempo después de refugiarse en Francia. Una voz de mujer es la protagonista y expresa su situación de angustia ante la persecución que ejercen sobre ella diferentes personajes para usurparle su identidad, sometidos a las órdenes del presidente Kouty. Se trata de un dictador, en un país indeterminado en el ámbito de Europa. Así lo expresa al inicio de la novela: «Je sais qu'ils finiront par me tuer. J'ai n'ai aucune idée du moment qu'ils choisiront pour le faire» (Orlea 1986: 9).

Cabe pensar, por las descripciones espaciales que se encuentran a lo largo de toda la novela, que el país puede ser Rumanía y que el dictador es Ceauşescu. La narradora principal y protagonista se llama Léontine, una joven de 20 años cuyos rasgos físicos son muy semejantes a los de la esposa del presidente Kouty. Léontine cae en desgracia ya que es detenida por su belleza y durante mucho tiempo estará a la disposición del servicio de seguridad del país totalitario y actuará de doble de la esposa del presidente, Bien-Aimée ${ }^{4}$. Esta situación se interrumpe cuando puede, después de muchos años, huir a otro país, igualmente no identificado pero que puede considerarse de lengua francesa, y muy posiblemente Francia.

Desde el punto de vista de la organización estructural, el universo narrativo presenta la complejidad de un relato plural articulado sobre movimientos yuxtapuestos. El relato marco está constituido por dos cuadros que pueden ser considerados como la presentación y el epílogo, en él se inserta otro relato principal organizado en tres partes. En este relato destacan tres grandes momentos que hacen evolucionar la anecdótica: el acecho y detención del personaje principal, la etapa de vida como doble de la mujer del dictador y la evasión y exilio en el país extranjero. En su conjunto todo el entramado enunciativo está articulado sobre diferentes voces masculinas y femeninas que dialogan y dan profundidad a la voz principal a la vez que introducen puntos de vista diversos y en ocasiones contradictorias (Vuillemin 2005).

Léontine se hace especialmente presente en el relato marco, en la presentación y en el epílogo. Desde el punto de vista temático, el relato comienza y termina del mismo modo: tras su huida y exilio en otro país vive obsesionada por una posible detención y por la preocupación de las consecuencias sobre ella. Las últimas frases de la novela vuelven a expresar la misma angustia que había sido manifestada al inicio: «Je veux, moi, une peur libre. La peur du libre arbitre. Je sais qu'ils finiront par me tuer. Je n'ai aucune idée du moment qu'ils choisiront pour le faire» (Orlea 1986: 251).

${ }^{4}$ El tema del desdoblamiento está también presente en la trilogía de los gemelos de Agota Kristof bajo la perspectiva de la gemelidad perversa en la que se proyecta, en el seno del sistema totalitario, la mentira y la sospecha frente a la falta de unidad, verdad y cohesión (Alfaro 2011). 
Léontine a lo largo del relato principal aparece en alternancia con otras voces que representan los distintos momentos de su vida. Merecen una especial atención, André, su pareja antes de ser detenida, Raoul, el marido impuesto, y Marc, el hijo de ambos, adiestrado por el sistema; todos ellos constituyen su vida privada, si bien siempre bajo la mirada del poder del Estado. Y por otra parte, en el ámbito del sistema dictatorial, observamos la presencia de personajes tipificados, despersonalizados, lo que muestra que son las marionetas del poder impuesto. En especial toda la atención se concentra en la pareja dictatorial que se convierte en el núcleo sobre el que gira la vida social y política del país representado. En su conjunto, la anecdótica presenta una dimensión múltiple: la vida de Léontine, junto a los demás personajes, como principal víctima del sistema, antes y después de haber sido privada de libertad y, en última instancia, la pareja de dictadores que aparecen descritos bajo la mirada de la caricatura (Steiciuc 2010: 146). Este despliegue de personajes cristaliza en el actante simbólico representado en la narración: el sistema totalitario y su deseada desaparición:

Tuer le Couple! Quel rêve débile et sans issue ! Un rêve que se fabriquent des milliers d'hommes et de femmes : avec l'habileté et l'inventivité extrêmes qu'ils mettent à atteindre l'orgasme, mais aussi avec une prudence extrême [...] Un rêve à trois : le Couple en tant qu'unité, le Voyeur, propriétaire en exclusivité de son petit cinéma, et l'Autre pour se charger d'un tel boulot. [...] Rêver à la mort du Couple est un rêve futile, un rêve bonbon que l'on ne peut pas sucer indéfiniment : il fond dans la réalité. [...] Il y avait déjà longtemps que nous avions renoncé à tuer le Couple.

La mort du Couple ne pouvait rien changer pour nous, ou si peu, que cela ne valait même pas un rêve. (Orlea 1986: 112-114)

El personaje de Léontine, considerada por la instancia del poder como la mejor doble que nunca había tenido Aimée (Orlea 1986: 89), queda descrito a través del cruce de miradas de los demás personajes y aparece progresivamente sometida al miedo y a la soledad sin ninguna posibilidad para expresarse. Por otra parte, dichas voces y miradas nos descubren las intrigas de la pareja dictatorial, su obsesión por retener a personas jóvenes que actúen como sus dobles para poder seguir manteniendo de manera ficticia su aspecto enérgico ante el pueblo y mantener vivo el mito fundador de la dictadura: «Intarissables sosies emboîtés d'un Couple éternel» (Orlea 1986: 192). En este sentido, el mito tiene continuidad en la medida en la que los diferentes personajes se enajenan, víctimas de un sistema que somete a las personas. Léontine, debido a su gran parecido con Aimée, pierde su identidad y se ve sometida a un miedo difícil de desarraigar:

Il lui fallut plus de temps pour reconnaître l'existence de la peur, différente de celle que régnait dans la ville; c'était une peur diffuse avec des poussées aigües. En fait, les habitants du Périmètre Zéro n'avaient qu'une peur, celle d'en être exclus. Dure et tranchante, leur peur se transformait en arme. Tous les habitants étaient armés de cette arme blanche. (Orlea 1986: 96-97) 
Así pues, tanto para Oana Orlea como para Léontine, el personaje de ficción, Francia es la tierra de adopción que da lugar a la palabra contra la violencia totalitaria.

\section{Rouja Lazarova}

Nace en 1968 en Sofía en el momento de la invasión soviética en Praga, momento en el que se intensifican las consecuencias del comunismo en los países de la Europa del Este. Durante su vida en Bulgaria ya había escrito en su lengua materna y durante ese periodo la palabra escrita le sirve para tomar conciencia y aspirar a la libertad. En 1990 recibe el Premio Prosa y Juventud por un conjunto de relatos breves en los que evoca su percepción de la realidad desde la ingenuidad juvenil. En 1991 abandona Bulgaria y se instala en París, donde obtiene el Diploma del Instituto de Estudios Políticos. Su actividad profesional es muy variada, es traductora, periodista social, corresponsal de la BBC y escritora. En 1998 publica su primera novela, Sur le bout de la langue, después seguirán las novelas: Cours croisés (2000), Frein (2002), Mausolée (2009) y Le muscle du silence (2015). Ha recibido diferentes reconocimientos literarios, entre ellos el Prix du Livre Numérique en el año 2000.

En un primer momento no aborda la experiencia totalitaria y prefiere incorporar otros aspectos relacionados con la experiencia en la sociedad de acogida: el proceso aprendizaje de la lengua, la integración cultural y el reconocimiento de la alteridad. Sin embargo, en sus últimas novelas, introduce la búsqueda de la propia identidad, las huellas dejadas por el totalitarismo y el deseo de denunciar la vida de las personas que durante varias décadas sufrieron sus terribles consecuencias.

Del mismo modo que hemos observado en la novela analizada de Oana Orlea, la temática del exilio y de la repercusión del sistema totalitario está presente bajo diferentes ángulos en las dos últimas novelas de Lazarova. En el caso de la novela Mausolée (2009), la autora describe la vida de tres generaciones de mujeres bajo el régimen búlgaro, después de la IIGM y hasta 2006. La autora narra los abusos de la dictadura socialista búlgara entre 1944 y 1990 bajo el culto al mausoleo de Georgi Dimitrov (1882-1949), padre de la patria socialista. Milena, la protagonista principal, cuenta en primera persona la vida de su abuela, Gaby, y de su madre, Rada, y ello hace que toda la novela transcurra entre el silencio y la sumisión de la generación de la madre y la abuela frente y la insumisión por medio de la palabra que asume la protagonista. Milena se convierte en la portavoz de las vidas no contadas y oprimidas por el Estado dictatorial (Alfaro 2013; 2014):

C'est dans l'extrême profondeur de ce silence, là où la vie n'existe plus, mais où, ma mère Rada et tant d'autres, nous avons vécu, que j'aimerais arriver au terme d'une longue apnée. J'aimerais sentir de nouveau le poids de cette masse épaisse de silence pour me rapprocher des protagonistes et les faire revivre. Mais comment raconter cette interminable litanie de jours anéantis par la peur de la parole? (Lazarova 2009: 18-19) 
En la última novela publicada por la autora, Le muscle du silence (2015), la protagonista es una mujer de edad media que vive en París desde hace una decena de años, proviene de un país del otro lado del Muro de Berlín que no queda definido. Debido a sus vivencias en el pasado, antes de su exilio en París, se enfrenta a todos los recuerdos obsesivos y a las consecuencias físicas que han tenido sobre ella el miedo, el poder y la falta de libertad simbolizada en la uniformización en todos los planos de la vida cotidiana: «Je ne voulais plus mentir sur mon passé, je voulais le ressusciter, aussi mortifère fût-il, mais je n'avais pas de souvernirs. De ma mémoire soufflait le vent sec du désert, qui me brûlait. Ne pas se souvenir était une torture» (Lazarova 2015: 16). Así pues, las dicotomías, silencio vs. palabra, memoria vs olvido, mentira vs verdad, miedo vs libertad, vuelven a ser los elementos estructuradores de todas las insatisfacciones, de un lado, y de los anhelos, de otro lado, de la protagonista:

Personne ne parlait. Ce qu'on m'apprenait, c'était à me taire.

On papotait, on baratinait, on rigolait, mais on ne parlait pas. Le socialisme avait développé chez l'homme un muscle du silence parce que les mots, une fois prononcés, pouvaient se retourner contre lui. [...] D'un individu à l'autre, il se développait différemment, mais il durcissait chez tous avec l'âge. [...] Dehors, l'équivalent de se taire, c'était mentir. [...] La peur avait déshumanisé la parole, lui avait enlevé sa fonction première, celle de communiquer les pensées et les sentiments. Ses fonctions sociales étaient demeurées, mais elles tissaient entre les individus une entente artificielle, reposant sur le soupçon. Le soupçon s'avéra un excellent liant social et un dynamiteur de l'esprit. Il morcelait la conscience en facettes, il la déstructurait. (Lazarova 2015: 32-33).

La novela, escrita en primera persona, narra a través de diez movimientos la evolución de esta mujer que se descubre a sí misma, explora su identidad y sus avatares durante las sesiones de psicoterapia a las que asiste: «Par où commecer? Qu'estce qui était important? Qu'est-ce qui allait révéler ce que je ne voulais pas voir?» (Lazarova 2015: 10). La novela transcurre entre dos hilos conductores: de un lado, el hilo anecdótico que hace progresar el relato, la protagonista se enamora del psiquiatra con el que hace la terapia; y de otro lado, la emergencia de todos los recuerdos y de todas aquellas palabras que han garantizado durante años la existencia del sistema comunista. A la vez, desde el punto de vista formal, hay un relato principal vinculado a la protagonista femenina y otro relato, integrado en el principal, que narra de manera discontinua y en letra cursiva los recuerdos del personaje masculino. Rino, judío de origen polaco que sobre vive a los campos de concentración, rememora, mediante una focalización interna, todos aquellos momentos que supusieron su paso por el campo de concentración en el momento de la IIGM, la desaparición de sus seres queridos, la liberación, su llegada a París, la posguerra y su vida posterior donde todos los recuerdos han seguido siendo indelebles:

J'avais compris que personne ne voulait savoir dès mon arrivée à l'hôtel Lutetia, en 1945. Les gens détournaient les yeux de la horde de squelettes pouilleux que nous étions. Alors je me sus tu. J'ai enferme tout ça dans un petit coffre-fort, à l'intérieur, et j'ai essayé de vivre. J'ai travaillé, j'ai toujours travaillé comme un détraqué. Mes collègues, mes 
amis, tout le monde ignorait. Je le cachais, je ne voulais pas qu'on pense que j'avais fait ma carrière grâce aux privilèges du survivant. Quand ils ont su la vérité, ils sont tombés à la renverse. (Lazarova 2015: 13)

El paralelismo con el personaje de Léontine de Oana Orlea es muy significativo, en la medida que dichas figuras de mujer son portavoces de la insatisfacción contra el sistema. Milena amplifica su mirada a través de los personajes femeninos que muestran las consecuencias del poder despótico de la figura masculina que representa el mito fundador de la patria. Y el personaje de su última novela, Przecinek, el nombre cariñoso que recibe de su psiquiatra, Rino, está descrito desde su capacidad de introspección y de análisis de la realidad vivida en el pasado. Para esta mujer lo importante es el lenguaje, la significación de las palabras para poder expresar por medio de la escritura, sabemos que está escribiendo una novela, aquello que fue inherente, la imposición del silencio, a un sistema impuesto por el terror. Los sentimientos que dicho sistema deja en ella son igualmente abordados: el miedo y la tristeza profunda, difíciles de desarraigar: «La tristesse m'envahissait toujours par surprise: je pleurais à l'intérieur, je pleurais, sans larmes, cette partie de moi qui n'avait pas vécu» (Lazarova 2015: 33). Y sobre todo el deterioro físico que se expresa a través de la enfermedad, la anorexia no superada hasta el momento y a la que se enfrenta también gracias a la posibilidad de identificar lo que la originó en el momento de su adolescencia: la falta de alimentos, el hambre y la irracionalidad de las cartillas de racionamiento y la carestía en general.

Finalmente, Lazarova, por medio de sus personajes de ficción Milena y Przecinek, deconstruye una identidad forjada en el silencio y reconstruye otra nueva identidad, fundamentada en el verdadero valor de las palabras en la sociedad europea de acogida.

\section{Conclusión}

Oana Orlea y Rouja Lazarova, a través de sus personajes femeninos, Léontine, Milena y Przecinek, así como de ellas mismas con sus experiencias personales, nos muestran el carácter regenerador del exilio en su dimensión plural: del país de origen, de la lengua y la cultura y de la ideología. Ellas impulsan un nuevo proyecto que reacciona contra el sistema de opresión y la imposición del silencio bajo el yugo del miedo a lo largo de varias décadas en Europa. Más allá del exilio, nuestras dos escritoras tienen en común el haber desarrollado desde una temprana edad un espíritu crítico en relación a la situación política y social vivida en sus respectivos países: la experiencia comunista y la voluntad de escribir en primera persona con el objetivo de contar sus vidas antes y después del exilio. Ambas escritoras, en el seno de la auto-ficción elaboran dos relatos que si bien formalmente presentan diferencias se construyen sobre la evidencia del realismo y la verosimilitud. Sus respectivos actos de escritura hacen convulsionar una etapa de la historia de Europa y subrayan la importancia de enunciar todas las palabras no dichas y los sentimientos reprimidos. 
Así pues, para terminar, podemos afirmar que el panorama literario europeo actual y el campo literario francófono, en particular, teje un nuevo paradigma caracterizado por la escritura de estas mujeres intelectuales para las que la lengua francesa se constituye en lengua de creación y de expresión en libertad. La lengua francesa deviene un cauce de expresión de una identidad nueva fuera del territorio vinculado a la represión y se propone como el medio para ejercer la palabra, cuestionar un sistema silenciado y escenificar las consecuencias perversas sobre los individuos.

\section{Referencias bibliográficas}

AleKsIÉviCH, Svetlana (2015): El fin del «Homo sovieticus». Barcelona: Acantilado.

ALFARO, Margarita (2011): «Gémellité, dédoublement et changement de perspective dans la trilogie d'Agota Kristof: Le grand cahier, La preuve, Le troisième mensonge». Çédille. Revista de Estudios franceses. Monografías 2: 283-306.

- (2012a): «Orlea, Oana», en Passages et ancrages en France. Dictionnaire des écrivains migrants de langue française (1981-2011), Ursula Mathis-Moser y Birgit Mertz-Baumgartner (dirs.), pp. 678-681. Paris: Honoré Champion.

- (2012b): «Lazarova, Rouja», en Passages et ancrages en France. Dictionnaire des écrivains migrants de langue française (1981-2011), Ursula Mathis-Moser y Birgit MertzBaumgartner (dirs.), pp. 523-525. Paris: Honoré Champion.

- (2013): «Literatura femenina en Europa. Representación literaria de las relaciones intergeneracionales: Fatima Mernissi. Rouja Lazarova», en Género y envejecimiento, Pilar Folguera et al. (eds.), pp. 82-90. Madrid: Ediciones de la UAM.

- (2014): «La construction d'un espace géo-poétique francophone en Europe: l'expérience totalitaire et la représentation de l'exil». Dedalus. Revista Portuguesa de Literatura Comparada 17-18, vol II: 1243-1260.

KUNDERA, Milan (1986): L'art du roman. Paris: Gallimard.

LAZAROVA, Rouja (2009): Mausolée. Paris: Flammarion.

- (2015): Le muscle du silence. Paris: Éditions Intervalles.

ORLEA, Oana (1986): Un sosie en cavale. Paris: Éditions du Seuil.

- (1992): Les années volées. Dans le goulag roumain à seize ans. Paris: Éditions du Seuil.

STEICIUC, Elena-Brânduşa (2010): «La Roumanie des années staliniennes dans les écrits de deux «Voix de l'exil». Rodica Iulian et Oana Orlea». Francofonia 58, primavera, 139147.

Vuillemin, Alain (2005): «Les voix narratives dans Un Sosie en cavale (1986) d'Oana Orlea», en La Francophonie dans les Balkans. Les Voix des femmes, Efstratia OktapodaLu y Vassiliki Lalagianni (dirs.), pp. 141-147. París: Publisud. 